\title{
A STUDY ON PHYSICAL EXERCISES TO IMPROVE PHYSICAL FITNESS FOR FEMALE ATHLETES OF TUG OF WAR IN HO CHI MINH CITY, VIETNAM
}

\author{
Nguyen Quang Vinh ${ }^{1 i}$, \\ Nguyen Quang Son ${ }^{2}$ \\ ${ }^{1}$ Associate Prof., \\ Ho Chi Minh City University of \\ Physical Education and Sports, \\ Vietnam \\ ${ }^{2}$ Associate Prof., \\ University of Economics Ho Chi Minh City, \\ Vietnam
}

\begin{abstract}
:
The paper used routine methods in the field of physical education and sports to identify 6 assessment tests and 14 physical activities aiming to enhance level of physical fitness for tug of war athletes in Ho Chi Minh City. After the experiment, the results indicated that the 14 physical activities have positive impact on the participants' fitness level.
\end{abstract}

Keywords: physical exercises, strength, tug of war, Ho Chi Minh City

\section{Introduction}

Tug of war is considered one of the most common and ancient folk sports (Li, 2015). It is a team sport that pits two teams against each other by motion of two legs of each player in a straight line and which can be played on a flat surface, having an indoor competition type on wooden floors or on neoprene mats or outdoor on dirt or grass courts. In an international tug of war, the upper body from the hips, back, arms, and chest is in a static state to fix the rope and the legs are always in a state of motion, the posture falling backwards with an angle of $45^{\circ}$ and the state of motion. Thus, the athletes should be required to maintain balance and good sense of space.

Especially, there are high requirements for cardiovascular and respiratory, good aerobic and anaerobic energy exchange capacity, strength of hands to hold the fixed rope, the soles of feet should be tightly close to the floor and the strength of two legs is used.

i Correspondence: email vinhqn@upes.edu.vn 
In international tug of war, athletes have to expend a lot of energy, so they only achieve best results when they store enough energy needed for the tournament.

The tournament is a confrontation competition that is for each weight class by gender and ends in the same session or in one day. Thus, when competing in many games with many opponents, accompanied by exertion (professional endurance), the amount of energy of athletes is not the same and depending on the match, on the opponent that the process of providing energy can be anaerobic without producing lactic acid and an aerobic process. The above condition shows that fitness is an important factor and determines the performance of athletes in tug of war. In order to prepare good physical fitness for athletes, it is necessary to have appropriate physical activities that are not only fit with the physiological and psychological characteristics of athletes but also suitable for the real conditions of facilities.

\section{Research design and method}

\subsection{Objectives of the study}

The study is aimed at finding out the suitable physical exercises for the female athletes who were members of a tug of war team in Ho Chi Minh city. The study results will be used as the training references enhancing best performance of tug of war team.

\subsection{Instruments and participants}

Research instruments used in this study were reference materials, questionnaire, physical fitness testing, experimental and statistics analysis.

The participants were 10 female athletes aged ranging from 16 to 18 years old who played for tug of war team in Ho Chi Minh city, Vietnam and 14 experts, coaches.

\section{Results and discussion}

\subsection{Selecting some physical development exercises for female athletes of tug of war team District 1, Ho Chi Minh City}

The selection of exercises is proceeded in 2 steps as follows.

Step 1: synthesizing physical development exercises in tug of war from various resources. However, tug of war is a relatively new sport so the documents about tug-ofwar are very limited, especially materials on physical development exercises. Therefore, we proceed as below:

- Piloting the questionnaire with 01 expert and 03 coaches who have experience in training tugging athletes in Ho Chi Minh City on the use of physical development exercises in tug of war.

- Based on the conditions of facilities, equipment for the study, characteristics of tug of war, physiological and physical characteristics of the research subjects, we designed 14 physical development exercises. 
Step 2: Delivering the questionnaire to 14 experts and coaches twice. The questionnaire was designed in the format of Two Likert Scale which were 'Agree' and 'Disagree'. Chi-square test $\left(\chi^{2}\right)$ of the 2 times of interview is presented in Table 3.1.

Table 3.1: Results of the questionnaire

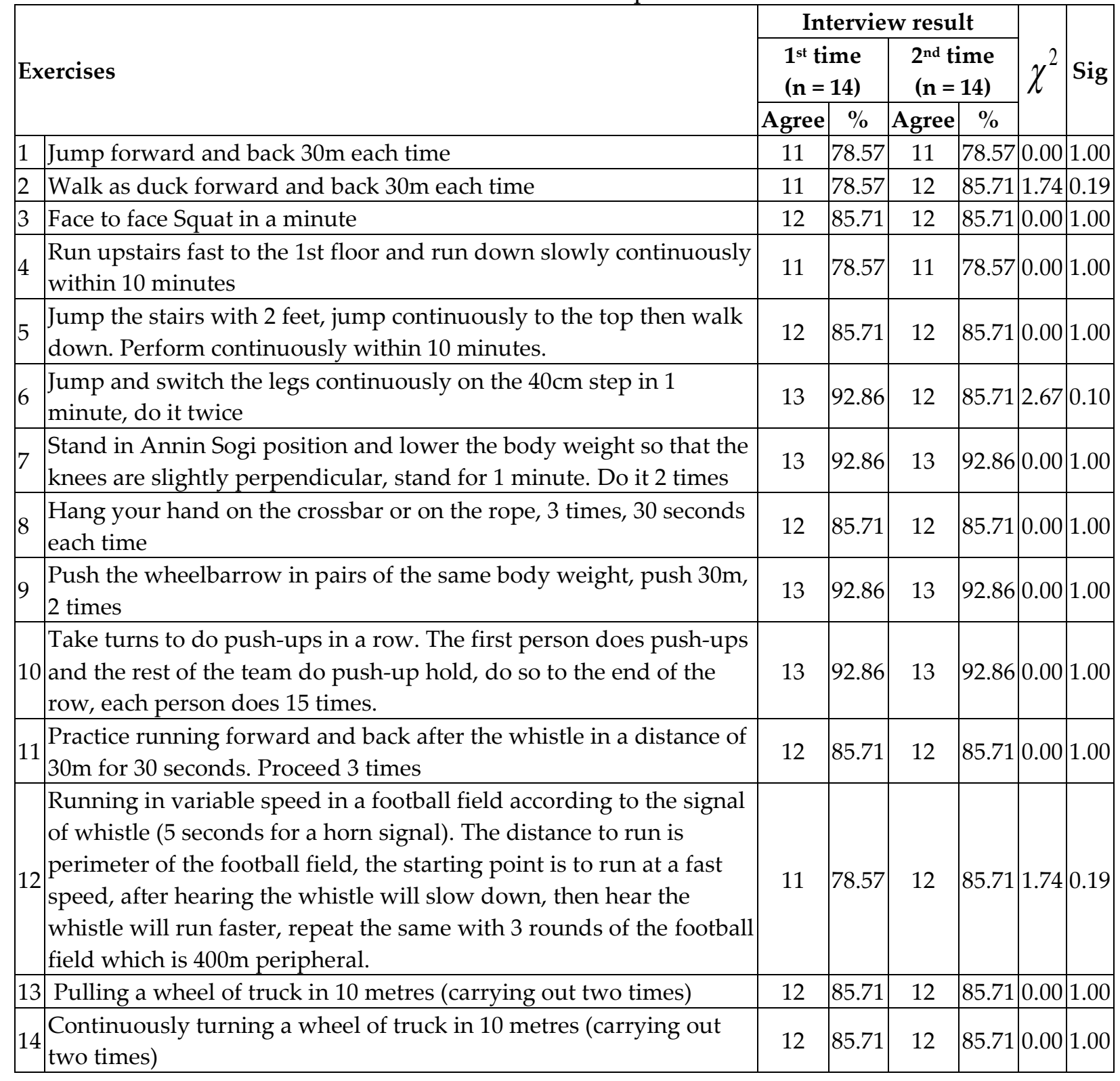

The results in Table 3.1 show that for all the tests with $\chi^{2}$ calculated value is less than $\chi^{2}$ from the table $(=3.84)$, sig $>0.05$, thus there is consistency between the 2 times of interview. From the results in Table 3.1, we decided to select 14 exercises above as the number of agreed votes was over $75 \%$ in both times. 


\subsection{Evaluate the effectiveness of the physical development exercises for the female athletes of tug of war team}

\subsubsection{Identify fitness tests for female athletes of the tug of war team}

The process was carried out in 3 steps:

Step 1: Synthesizing of tests to assess the physical fitness level of the athletes from different authors. Due to the late introduction of International Tug-of-war sport to Vietnam, there are few studied found been found in the field. To select the tests, we have reviewed some previous researches such as Nguyen Ngoc Cu (1998); Nguyen The Truyen, Nguyen Kim Minh \& Tran Quoc Tuan (2002), Tony Martin (2009) and Doan Cong Tuan (2011). Furthermore, based on the features of tug of war, facilities for the research, we decided to choose 7 tests for evaluation physical fitness.

Step 2: Consulting with 14 experts and coaches through a questionnaire two times. The questionnaire was designed in the format of 'Agree' and 'Disagree'. The results of Chi-square test $\left(\chi^{2}\right)$ of the 2 times of interview are presented in Table 3.2 below.

Table 3.2: The results of questionnaire consulting experts and coaches about the selection of tests

\begin{tabular}{|c|c|c|c|c|c|c|}
\hline \multirow{3}{*}{ Tests } & \multicolumn{4}{|c|}{ Interview result } & \multirow{3}{*}{$\chi^{2}$} & \multirow{3}{*}{ Sig } \\
\hline & \multicolumn{2}{|c|}{$\begin{array}{l}1^{\text {st }} \text { time } \\
(\mathrm{n}=14)\end{array}$} & \multicolumn{2}{|c|}{$\begin{array}{c}2^{\text {nd }} \text { time } \\
(\mathrm{n}=14)\end{array}$} & & \\
\hline & Agree & $\%$ & Agree & $\%$ & & \\
\hline \begin{tabular}{l|l}
1 & Right-handed force $(\mathrm{Kg})$ \\
\end{tabular} & 11 & 78.57 & 11 & 78.57 & 0.00 & 1.00 \\
\hline $\begin{array}{ll}2 & \text { Left-handed force }(\mathrm{Kg}) \\
\end{array}$ & 11 & 78.57 & 12 & 85.71 & 1.74 & 0.19 \\
\hline 3 Push-ups in 1 minute (times) & 12 & 85.71 & 12 & 85.71 & 0.00 & 1.00 \\
\hline 4 Step up stairs in 1 minute (times) & 11 & 78.57 & 11 & 78.57 & 0.00 & 1.00 \\
\hline $\begin{array}{ll}5 & \text { Leapfrogging } 30 \mathrm{~m} \text { (seconds) } \\
\end{array}$ & 12 & 85.71 & 12 & 85.71 & 0.00 & 1.00 \\
\hline 6 Duck walking 30m (seconds) & 13 & 92.86 & 12 & 85.71 & 2.67 & 0.10 \\
\hline 7 Single rope skipping for 2 minutes (times) & 10 & 71.43 & 10 & 71.43 & 0.00 & 1.00 \\
\hline
\end{tabular}

The results in table 3.1 show that the tests $\chi^{2}$ calculated value is less than $\chi^{2}$ from the table $(=3.84)$, sig $>0.05$, thus there is consistency between the 2 times of interview. From the results in Table 3.2, we decided to choose those tests with $75 \%$ of the experts' agreement. Six tests were selected including: Right-handed force (Kg), Left-handed force (KG), Pushups in 1 minute (times), Step up stairs in 1 minute (times), Duck walking 30m (seconds), Duck walking 30m (seconds).

Step 3: Check the reliability of the tests.

In order to determine the reliability of the tests, the athlete participants were tested 2 times, the time between the two intervals was 5 days, the test conditions between the two times were the same. Then, the correlation coefficient (r) of the content of the two tests will be calculated and the test results are presented in Table 3.3. 
Table 3.3: Reliability of physical fitness assessment tests for female athletes of tug of war team

\begin{tabular}{|c|l|c|c|c|c|}
\hline No & Tests & $\begin{array}{c}\mathbf{1}^{\text {st }} \mathbf{t i m e} \\
\bar{X} \pm S\end{array}$ & $\begin{array}{c}\mathbf{2}^{\text {nd }} \mathbf{\text { time }} \pm S \\
\bar{X} \pm S\end{array}$ & r & sig \\
\hline 1 & Right-handed force (Kg) & $31.10 \pm 6.14$ & $30.90 \pm 5.90$ & 0.99 & 0.00 \\
\hline 2 & Left-handed force (Kg) & $25.40 \pm 4.81$ & $25.90 \pm 4.58$ & 0.95 & 0.00 \\
\hline 3 & Push-ups in 1 minute (times) & $25.80 \pm 3.52$ & $26.10 \pm 3.07$ & 0.91 & 0.00 \\
\hline 4 & Step up stairs in 1 minute (times) & $118.40 \pm 14.96$ & $118.80 \pm 11.86$ & 0.96 & 0.00 \\
\hline 5 & Leapfrogging 30m (seconds) & $18.86 \pm 1.78$ & $18.88 \pm 1.80$ & 0.96 & 0.00 \\
\hline 6 & Duck walking 30m (seconds) & $26.66 \pm 1.93$ & $26.42 \pm 1.81$ & 0.96 & 0.00 \\
\hline
\end{tabular}

The results from Table 3.3 revealed that the six tests were reliable $(0.91 \leq|r| \leq 0.99$ and Sig<0.05).

Physical fitness is an important determinant of athletes'performance. Due to the actual requirements of the competition, players who want to attack, defend, and counterattack must master a variety of techniques, so they must have a solid level of physical fitness. A tug of war athlete must be 'as fast as a short distance runner and as strong as a weightlifter, as enduring as a long distance runner, as flexible as an acrobat". It means that tug of war athletes must move quickly, have good physical fitness and flexibility to win. Therefore, the above tests are very suitable for assessing the physical fitness of tugof-war athletes.

\subsubsection{Evaluation of the effectiveness of physical development exercises for female athletes of the tug of war team}

\subsubsection{Building the experimental plan}

We developed the procedure to conduct the experimental training with the selected exercises. The 10 athletes of tug of war received 3-month training with 3 sessions a week and each session lasted 2 hours. To assess the effectiveness of these exercises, the tests selected above were used. The results of pre-training and post-training were compared and presented in Table 3.4 below.

Table 3.4: The comparison of assessment tests before and after the experimental training

\begin{tabular}{|c|l|c|c|c|c|c|}
\hline \multirow{2}{*}{ No } & \multirow{2}{*}{ Tests } & Before the experiment & \multicolumn{3}{|c|}{ After the experiment } \\
\cline { 3 - 7 } & & $\bar{X} \pm \mathbf{S}$ & $\bar{X} \pm \mathbf{S}$ & $\bar{W}$ & $\mathbf{t}$ & Sig \\
\hline 1 & Right-handed force $(\mathrm{Kg})$ & $31.10 \pm 6.14$ & $33.60 \pm 6.47$ & 6.14 & 3.77 & 0.00 \\
\hline 2 & Left-handed force $(\mathrm{Kg})$ & $25.40 \pm 4.81$ & $27.60 \pm 4.74$ & 5.64 & 4.12 & 0.00 \\
\hline 3 & Push-ups in 1 minute (times) & $25.80 \pm 3.52$ & $27.90 \pm 2.81$ & 8.20 & 3.71 & 0.00 \\
\hline 4 & Step up stairs in 1 minute (times) & $118.40 \pm 14.96$ & $126.90 \pm 11.50$ & 7.27 & 4.41 & 0.00 \\
\hline 5 & Leapfrogging 30m (seconds) & $18.86 \pm 1.78$ & $17.93 \pm 1.63$ & 4.07 & 5.29 & 0.00 \\
\hline 6 & Duck walking 30m (seconds) & $26.66 \pm 1.93$ & $25.73 \pm 1.95$ & 3.56 & 4.31 & 0.00 \\
\hline $\bar{W}$ & & 5.81 & & \\
\hline
\end{tabular}


The data in Table 3.4 show that after the experimental training, the physical fitness levels of all female athletes of the tug of war team increased and the figures were statistically significant different before the experiment and after the experiment (sig < 0.05). The results indicated that the fitness level of these players gained some improvement after the treatment with $\bar{W}=5.81 \%$. Among the selected tests, push-ups had the highest improvement level with $\bar{W}=8.20 \%$ ) meanwhile the test duck walking gained the lowest score of development with $\bar{W}=3.56 \%$.

The results of specific tests after the experimental training are presented in Figure 3.1 below.

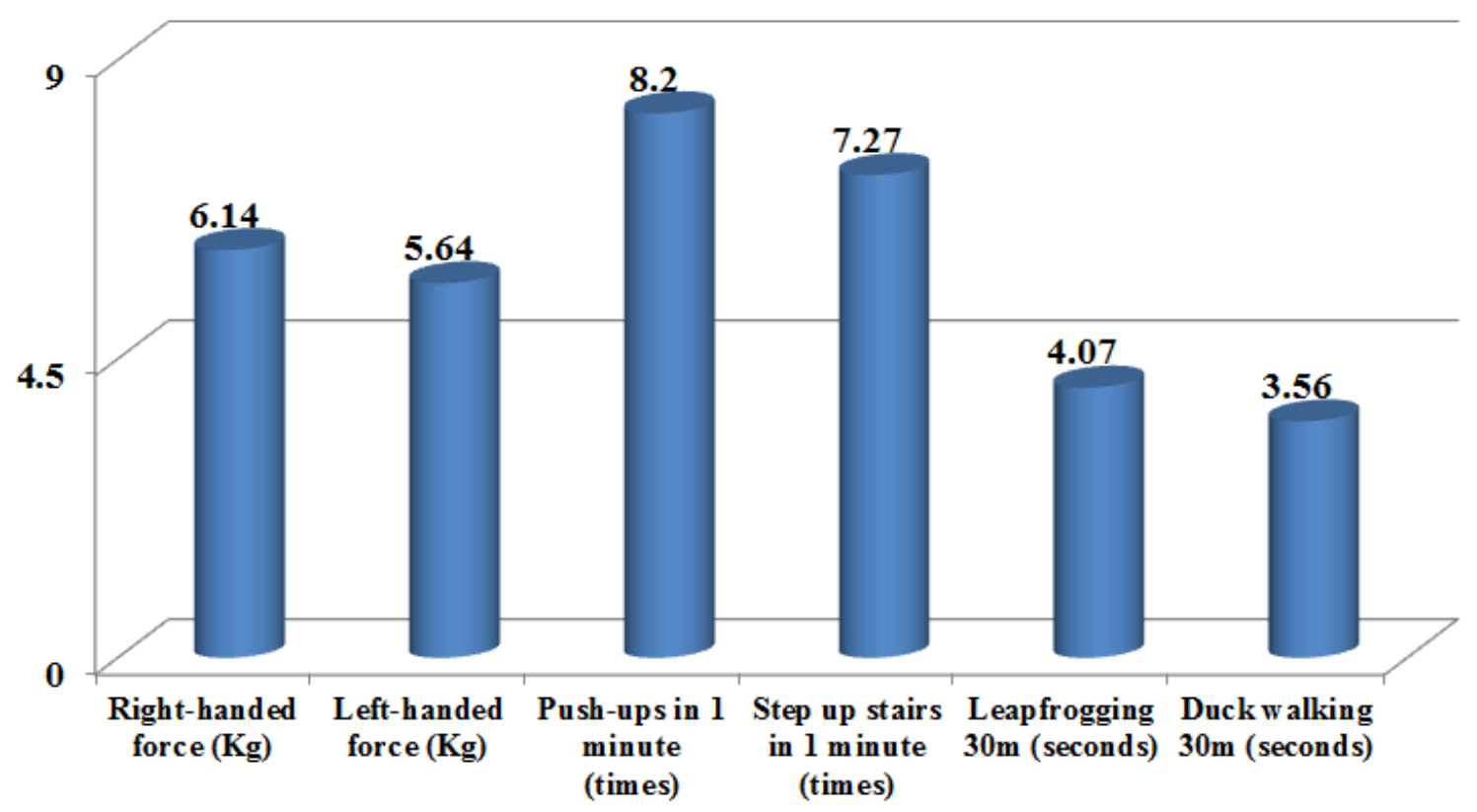

Figure 3.1: Results of specific tests after experimental training

In short, the results show that the twelve physical exercises have positive impact on the physical development of the athlete subjects and they could be employed for training these players of tug of war.

\section{Conclusion}

The study figured out 14 selected physical exercises employed for training the physical fitness for the female athletes of tug of war. In addition, the study also decided six tests used to assess the physical fitness for these subjects.

The results after the treatment revealed that the 14 physical exercises had positive effect on the physical fitness level of the tug of war athletes of a team in Ho chi Minh city. The mean development level is found $\bar{W}=5.81 \%$ in which push-ups gained the highest level with $\bar{W}=8.20 \%$ ) meanwhile the test duck walking was recorded the lowest score of development with $\bar{W}=3.56 \%$. 


\title{
Conflict of Interest Statement
}

The authors declare no conflicts of interests for this study.

\begin{abstract}
About the Authors
Nguyen Quang Vinh is Associate Professor, Academic Affairs, Ho Chi Minh University of Physical Education and Sports. His research interests include physical education, teachers' beliefs and PE curriculum planning.

Nguyen Quang Son is Associate Professor, Physical Education Department, University of Economics. His research interests are mainly in physical education and teacher development.
\end{abstract}

\section{References}

1. B. Liu, and X. Du (2003), "The biomechanics analysis of tug-of-war technology," Journal of Nanjing Institute of Sport (Natural Science Edition), vol. 2, no. 3.

2. Nguyen, Ngoc Cu et al. (1998), Science of selecting sport talents-Volume 2, Institute of Sport Science.

3. Nguyen The Truyen, Nguyen Kim Minh, Tran Quoc Tuan (2002), Standards for assessing training qualifications in sports selection and training, Sports Publishing House, Hanoi.

4. Doan Cong Tuan (2011), Research on developing content and selection criteria for the initial specialized stage for female athletes in Ho Chi Minh City's tug of war team aged 16-18, M.A thesis in Education, Bac Ninh University of Sports.

5. Tony Martin (2009), TWIF Guide Tug of war for Junior - Tug of war international Federation

6. 教培方案的基本拉有限公司 TUG OF WAR (2008), 中华协会共同拉

7. J. Li (2002), "Tug-of-war sport new test," Journal of Sport Culture Trib- une, vol. 15, no. 5 , pp. 92.

8. P. Shen (2010), "The mechanics analysis of tug-of-war," Physics Teach- ers, vol. 31, no. 10.

9. Xinyu Li (2015), The origin, Development and Winning skills of Tug of War. The Open Cybernetics \& Systemics Journal, Vol.9, 2021-2024.

10. Weston AT (1997), Petosa R. Pate RR. Validation of an instrument for measurement of physical activity in youth. Medicine and Science in Sports and Exercise 1997;29(1):138-143. 
Nguyen Quang Vinh, Nguyen Quang Son

A STUDY ON PHYSICAL EXERCISES TO IMPROVE PHYSICAL FITNESS

FOR FEMALE ATHLETES OF TUG OF WAR IN HO CHI MINH CITY, VIETNAM

Creative Commons licensing terms

Authors will retain the copyright of their published articles agreeing that a Creative Commons Attribution 4.0 International License (CC BY 4.0) terms will be applied to their work. Under the terms of this license, no permission is required from the author(s) or publisher for members of the community to copy, distribute, transmit or adapt the article content, providing a proper, prominent and unambiguous attribution to the authors in a manner that makes clear that the materials are being reused under permission of a Creative Commons License. Views, opinions and conclusions expressed in this research article are views, opinions and conclusions of the author(s). Open Access Publishing Group and European Journal of Physical Education and Sport Science shall not be responsible or answerable for any loss, damage or liability caused in relation to/arising out of conflict of interests, copyright violations and inappropriate or inaccurate use of any kind content related or integrated on the research work. All the published works are meeting the Open Access Publishing requirements and can be freely accessed, shared, modified, distributed and used in educational, commercial and non-commercial purposes under a Creative Commons attribution 4.0 International License (CC BY 4.0). 